\title{
Assessment of liver function, bile secretory rate and liver histological changes in type 1 diabetes mellitus rats treated with ocimum gratissimum
}

\author{
Uduak Akpan Okon', Aniekan Imo Peter², Esther Olusola Aluko' \\ ${ }^{1}$ Department of Physiology, Faculty of Basic Medical Sciences, College of Health Sciences, University of Uyo, Uyo, Nigeria, ${ }^{2}$ Department of \\ Anatomy, Faculty of Basic Medical Sciences, College of Health Sciences, University of Uyo, Uyo, Nigeria
}

\section{A B S T R A C T}

Background: The liver plays an important role in nutrient metabolism and alterations in the liver function, biliary secretion and cyto-architecture are common in diabetes mellitus (DM). Aim: Ocimum gratissimum (OG) has been reported to exert hypoglycaemic effect in DM. The study was undertaken in order to assess the impact of OG in the treatment of diabetic complications. Materials and Methods: Phytochemical and toxicity tests were conducted. Eighteen rats divided into three groups of six rats each were used. Group 1 was the control and given normal feed only. Group 2 was diabetic untreated rats (DM) while group 3 was OG treated diabetic rats (DMT) at a dose of $1500 \mathrm{mg} / \mathrm{kg}$. All groups had access to food and water ad libitum. After 28 days, serum was obtained for analysis of alkaline phosphatase $(A L P)$, alanine aminotransferase $(A L T)$ and aspartate aminotranferase (AST). The bile content was collected at 3 hours interval to determine the bile secretory rate. Routine biopsy method was employed for histological studies. Results: Results showed that AST in the DM and DMT groups were significantly higher $(P<0.001)$ than the control group; DM was significantly higher $(P<0.001)$ than the DMT. ALT and ALP levels in DM and DMT groups were significantly $(P<0.001)$ higher than the control; DM was significantly higher $(P<0.001)$ than DMT. Conclusion: Structural and functional hepatic impairments were observed in DM. OG treatment appeared to effectively ameliorate these complications including enhancement of bile secretion.

Key words: Bile secretion, Liver function test, Liver histology, Ocimum gratissimum, Type 1 diabetes mellitus

\section{INTRODUCTION}

Alterations in the function of the liver and biliary secretion are common in DM. Since the liver plays an important role in glucose metabolism, it is therefore, not surprising that DM can affect hepatic function and that glucose metabolism can be altered in liver disease. In some cases chronic liver disease and DM may result from the same cause. ${ }^{1}$

Hepatocytes contain many enzymes which may be released into the blood during pathological processes. Measurement of their activity in the blood may give evidence of hepatobiliary disease. In practice, maximal information is obtained by measuring the activity of relatively few enzymes. However, none of these enzymes is specific to the liver and alternative origins should be considered particularly where abnormalities have been found incidentally in patients with no clinical evidence of liver disease. ${ }^{2}$

Alanine aminotransferase (ALT), a cytoplasmic enzyme and aspartate aminotransferase (AST), present both in cytoplasm and mitochondria are the two important aminotransferases. Normal plasma contains low activities of both enzymes, the source of which is unknown. Neither of the enzymes 
is specific to the liver, but ALT occurs in much higher concentration in the liver than elsewhere and consequently increased serum ALT activity specifically reflects hepatic damage. ${ }^{2}$ ALT and AST are liberated into the blood whenever liver cells are damaged and increased plasma enzyme activity is a sensitive index of hepatic damage. Alkaline Phosphatase is situated principally in the canalicular and sinusoidal membranes of liver cells. Blood normally contains alkaline phosphates derived mainly from bone and liver, and in pregnancy additional activity of placental origin is found. About a fifth of people have plasma alkaline phosphatase of intestinal origin and its activity may increase after meals.

When hepatocytes are damaged, minute quantities of alkaline phosphatase is liberated into the blood, most probably coming from dead cells. Consequently, plasma alkaline phosphatase activity does not usually rise more than two fold in acute or chronic hepatocellular disease. ${ }^{3}$ In biliary tract, obstruction at any level results in synthesis of new alkaline phosphatase in the hepatocyte membrane, much of which escapes in to the blood. ${ }^{4}$ A greatly increased plasma alkaline phosphatase activity is therefore, the main biochemical indicator of biliary obstruction though it provides no information about the site of that obstruction.

The major histological finding so far reported is glycogenic infiltration of the liver cell nuclei, which resembles vacuolization. This occurs in about $2 / 3^{\text {rd }}$ of Type I DM, due to increase in glycogen deposition in poorly controlled diabetes. ${ }^{5}$ Very poor diabetic control is associated with an increased water content in hepatocytes, probably in order to keep the glycogen in solution.

Since, liver functions, biliary secretion and cyto-architecture have been reported to be altered in DM, and OG has been reported to exert hypoglycaemic effect in DM, the need to therefore assess the impact of OG treatment on these diabetic complications will enable identification of alternative treatment therapies.

\section{MATERIAL AND METHODS}

Plant materials and preparation of aqueous extract The leaves of Ocimum gratissimum were obtained from the University of Calabar Botanical Garden and identified by the Chief Herbarium Officer of Botany Department of University of Calabar. The fresh leaves were rinsed with water to remove sand and debris and then allowed to air dry. The leaves were then dried under shade for two days and then transferred into Astell Hearson Oven and dried at a temperature range of $40-45^{\circ} \mathrm{C}$.

The dried leaves were then ground in an electric blender into fine powder to give a gram weight of $527 \mathrm{~g}$, which was soaked overnight with regular stirring for 15 hours in 2.65 liters of distilled water. The mixture was filtered using a satin mesh material and the final filtrate was obtained by filtering through a Whatman's filter paper size 1. The final filtrate was dried in the Astell Hearson Oven at $45^{\circ} \mathrm{C}$ to obtain a brown gummy paste. A mettler P163 electronic weighing balance was used to weigh the gummy paste before stock solution was prepared. The stock solution of the extract was prepared by dissolving $15 \mathrm{gm}$ of extract in $10 \mathrm{ml}$ of water to give a concentration of $1500 \mathrm{mg} / \mathrm{ml}$. The stock solution was labeled appropriately and refrigerated at $4^{\circ} \mathrm{C}$ until required for use. The median lethal dose $\left(\mathrm{LD}_{50}\right)$ of the plant extract was determined by method of Lorke (1983). ${ }^{6}$

\section{Determination of phytoconstituents}

The phytoconstituents of the extracts was determined and were screened for the presence of carbohydrates, tannins, alkaloids, saponins, phenolics, anthraquinones and cardiac glycosides as described by Trease and Evans $(1984)^{7}$ and Sofowora (1984). ${ }^{8}$

Animal preparation, experimental groupings and treatment

Eighteen male albino wistar rats were used for the study, the animals were divided into three groups of 6 rats each and were assigned randomly into each group and housed in cages assigned to them.

The first group was made up of the control animals which were fed with normal rat chow (feed). The second group contained streptozotocin induced diabetic rat which were left untreated. The third group of animals contained the test group which were streptozotocin induced diabetic rats treated with aqueous leaf extract of Ocimum gratissimum. The experimental procedures involving the animals and their care were in line with the approved guidelines by the University of Uyo, Akwa Ibom State research and ethical committee established and guided by the Helsinki Declaration on Animal research.

\section{Induction of diabetes mellitus}

Type I diabetes mellitus was induced in twelve male albino wistar rats by a single injection of $65 \mathrm{mg} / \mathrm{kg}$ streptozotocin. The injection was given intraperitoneally. The state of diabetes was observed after 48 hours by the symptoms of polyuria and glucosuria and this state was confirmed using uristic test strip (Bayer Health Care LLC, USA). Also, the blood glucose level was tested 1 week after induction using a Glucometer (ACCU-CHECK Advantage II, Roche Diagnostics (GmbH, Germany) and ACCU-CHECK Advantage II test strips.

\section{Extract administration and observation}

One week after induction of diabetes in the 12 male albino wistar rats, the extract was administered orally to the 
DMT group at a dose of $1500 \mathrm{mg} / \mathrm{kg}$ body weight daily for 28 days. Administration was facilitated by the use of a syringe and orogastric tube.

\section{Liver function tests}

Blood was collected by cardiac puncture of the anaesthetized (sodium thiopentone, Rolex Medial GMBH Germany) animals. Blood samples from each rat were collected using syringes and needles and separated into sample bottles and allowed to stand for 30 minutes for clotting to take place and then centrifuged. The serum extracted into fresh test tubes and stored in a refrigerator for analysis of alkaline phosphatase (ALP), alanine aminotransferase (ALT) and aspartate aminotranserase (AST).

\section{Measurement of alkaline phosphatase}

This was by the optimized standard method recommended by the deutsche Geseiischage fur Klinishche Chemic GSCC (1972). P-nitrophenyl phosphate is hydrolysed to phosphate and p-nitrophenol in the presence of ALP. A calculated amount of sample $0.01 \mathrm{ml}$ in a test tube was mixed with reagent $(0.5 \mathrm{ml})$ containing the substrate $\mathrm{p}$-nitrophenyl phosphate and brought to room temperature. The solution was mixed, initial absorbance read after 1 minute. The reaction was allowed to stand for 3 minutes and the absorbance read again at $405 \mathrm{~nm}$. Alkaline phosphates activity was calculated from.

$\mathrm{UL}=2760 \times \Delta$ Anm $/$ minute micro

$\mathrm{UL}=$ Unit of aklaine phosphatase affinity

$\Delta \mathrm{A}=$ Change in absorbance

\section{Measurement of alanine and aspartate transferase}

The measurement of AST and ALT activities in the serum were done using endpoint colorimetric-diagnostic kit (Randox; Labouratories UK) based on Reitman and Frankel (1952) ${ }^{10}$ method. ${ }^{9}, 10$ The pyruvate produced by transamination reaction between L-alanine and ketoglutarate reacts with 2 , 4, dinitrophenyl hydrazine to give a coloured hydrazone, which represents alanine aminotransferase activity. The oxaloacetate hydrazone formed with 2, 4 dinitrophenyl hydrazine is used to measure aspartate aminotransfarase (AST). Both AST and ALT were read at $540 \mathrm{~nm}$ wavelength.

\section{Histology of the liver}

Permanent preparations using routine biopsy method ${ }^{10}$ was employed. Tissue sections were treated with traditional haematoxilin and eosin stains. Other special stains used included silver, reticulum, trichrome and Periodic Acid Schiff (PAS).

\section{Estimation of bile secretory rate}

Biliary secretion was collected by the method of Vickers et al, (1998). ${ }^{11}$ The rats were starved for 12 hours prior to the time of experiment. The animals were weighed and anaesthetized by intraperitoneal administration of sodium thiopentone ( $6 \mathrm{mg} / 100 \mathrm{~g}$ body weight), and were quickly pinned to a dissecting board for a tracheostomy performed to clear the airway for easy breathing. The stomach was opened along the linea alba to prevent bleeding. A laparotomy was performed and the liver lobes deflected anterolaterally to expose the common bile duct. The common bile duct was then cannulated with a portex cannula $(0.5 \mathrm{~mm}$ in diameter) after a small incision was made. The cannula was held in place with a thread tied round the bile duct. The bile content was collected at 3 hours interval for each group studied to determine the rate of bile secretion.

\section{Statistical analysis}

All results are presented as mean \pm standard error of mean. Three sets of data were analyzed using one way ANOVA, followed by the least significant difference (LSD) procedure for significant $F$ values, $(\mathrm{P}<0.05)$ was considered significant. Computer software SPSS and Excel Analyzer was used for the analysis.

\section{RESULTS}

Aspartate aminotransferase (AST) levels in the various experimental groups

The mean AST levels in the control, DM and DMT groups were: $42.166 \pm 0.601,64.667 \pm 0.988$ and $50.667 \pm 3.16 \mathrm{IU} / \mathrm{L}$ respectively. There were significant differences between all the groups. The DM and DMT groups were significantly higher $(\mathrm{P}<0.001)$ than the control group. The DM was significantly higher $(\mathrm{P}<0.001)$

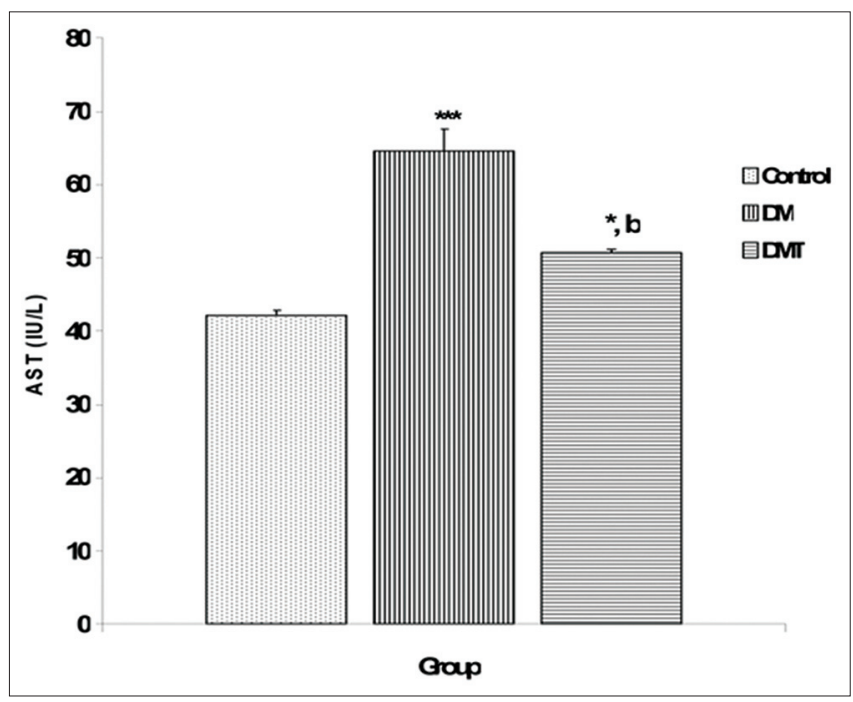

Figure 1: Comparison of aspartate amino transferase (AST) concentration in the different experimental groups. ${ }^{* *} \mathrm{P}<0.01$, ${ }^{*} \mathrm{P}<$ 0.05 vs control; $\mathrm{b}=\mathrm{P}<0.001$ vs $\mathrm{DM}$ 
than the DMT, Figure 1.

Alanine aminotransferase (ALT) levels in the control, DIM and DMT experimental groups of rats

The mean values of ALT were: $36.5 \pm 0.763,60.3 \pm 0.843$ and $46.8 \pm 2.844$ for control, DM and DMT groups respectively. There were significant differences between all the groups. Test groupsweresignificantlyhigher $(\mathrm{P}<0.001)$ than thecontrol.DMT wassignificantlyhigher $(\mathrm{P}<0.01)$ thancontrol.DMwassignificantly higher $(\mathrm{P}<0.001)$ than DMT, Figure 2.

Estimation of alkaline phosphatase (ALP) levels in the different experimental groups of rats

The mean values of ALP in the control, DM and DMT groups were: $162.3 \pm 0.802,398.5 \pm 21.531$ and $536.5 \pm 27.212 \mu \mathrm{mol} / \mathrm{L}$ respectively. The $\mathrm{DM}$ was significantly higher $(\mathrm{P}<0.001)$ than the control. The DMT was significantly higher $(\mathrm{P}<0.01)$ than the DM group, Figure 3.

The rate of bile secretion in the different experimental groups of rats

The results of the rate of bile secretion in the control, diabetic and diabetic treated groups were $0.005+6.7$, $0.004+1.1$ and $0.007+1.3 \mathrm{l} / \mathrm{hr}$ respectively. There was significant $(\mathrm{P}<0.001)$ increase in bile secretory rate in the DMT group compared to the control and DM groups. The DM group was significantly $(\mathrm{P}<0.0001)$ higher than the control, Figure 4.

Histology of the liver in the control, DIM and DIMT groups

Histological findings of the liver reveal normal liver in the control group. Some minor pathological features

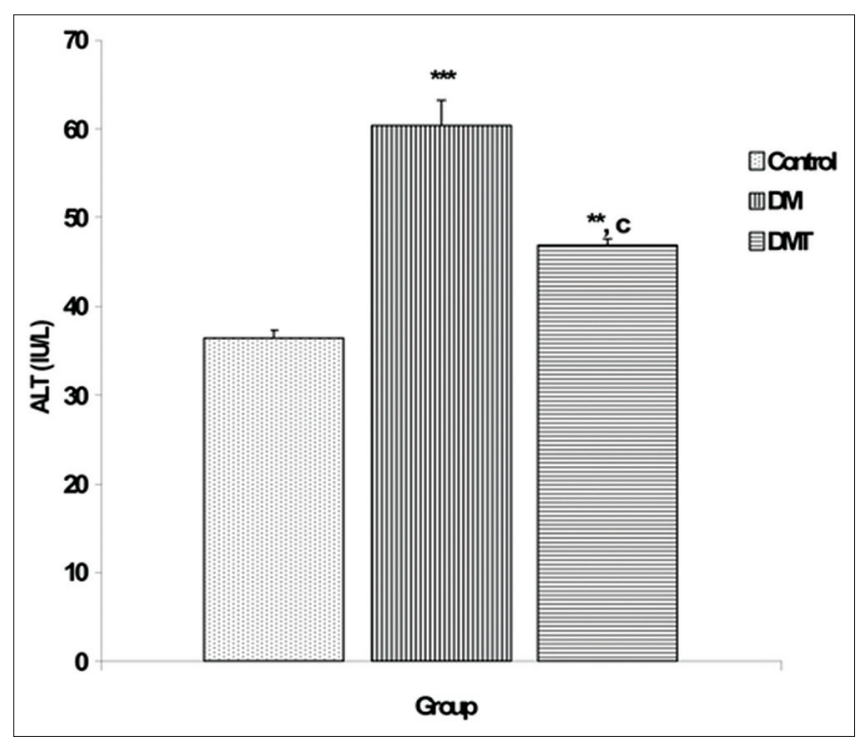

Figure 2: Comparison of alanine amino transferase (ALT) concentration in the different experimental groups. ${ }^{* * *} \mathrm{P}<0.001$; ${ }^{* *} \mathrm{P}<0.01$ vs control; $\mathrm{C}=\mathrm{P}<0.001$ vs DM were however, noticeable in the DM and DMT groups, Figures 5-7.

\section{DISCUSSION}

The liver enzymes measured in this study included aspartate amino transferase (AST), alanine amino transferase (ALT) and alkaline phosphatase (ALP). The result showed

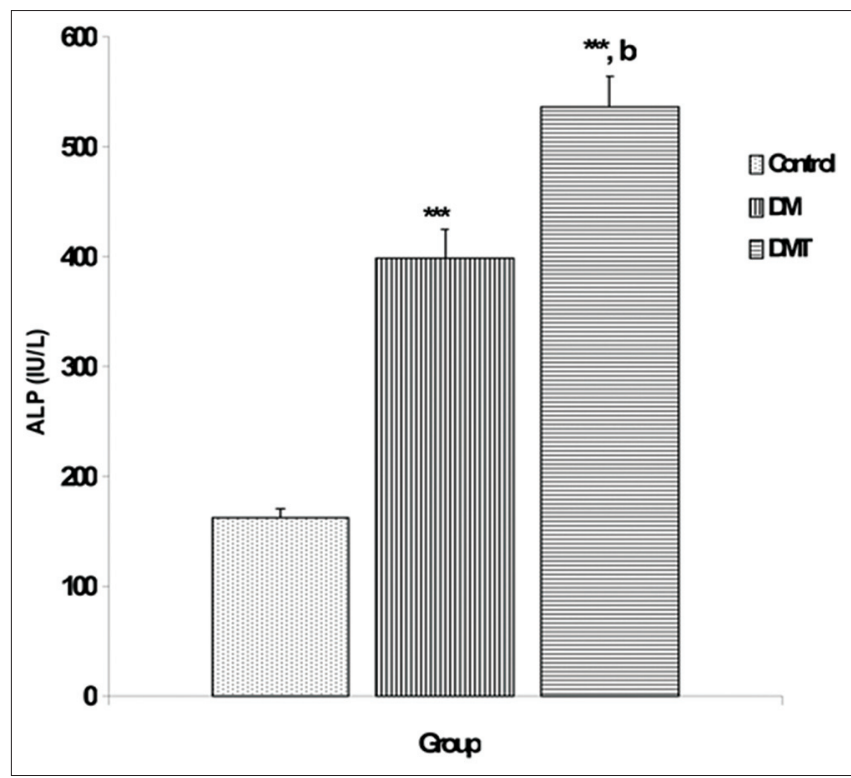

Figure 3: Comparison of alkaline phosphate (ALP) concentration in the different experimental groups. ${ }^{* \star} P<0.001$ vs control; $b=P<0.01$ vs DM

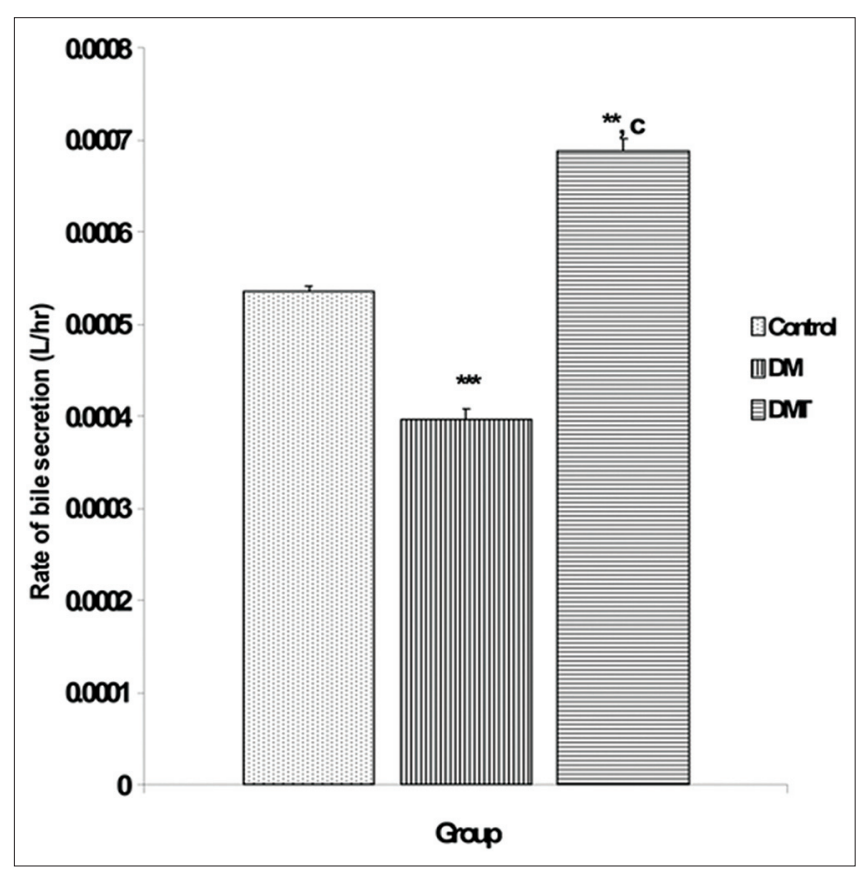

Figure 4: Comparison of rate of bile secretion in the different experimental groups. ${ }^{\star * *} \mathrm{P}<0.001$, ${ }^{\star *} \mathrm{P}<0.01$ vs control; $\mathrm{C}=\mathrm{P}<0.001$ vs DM 


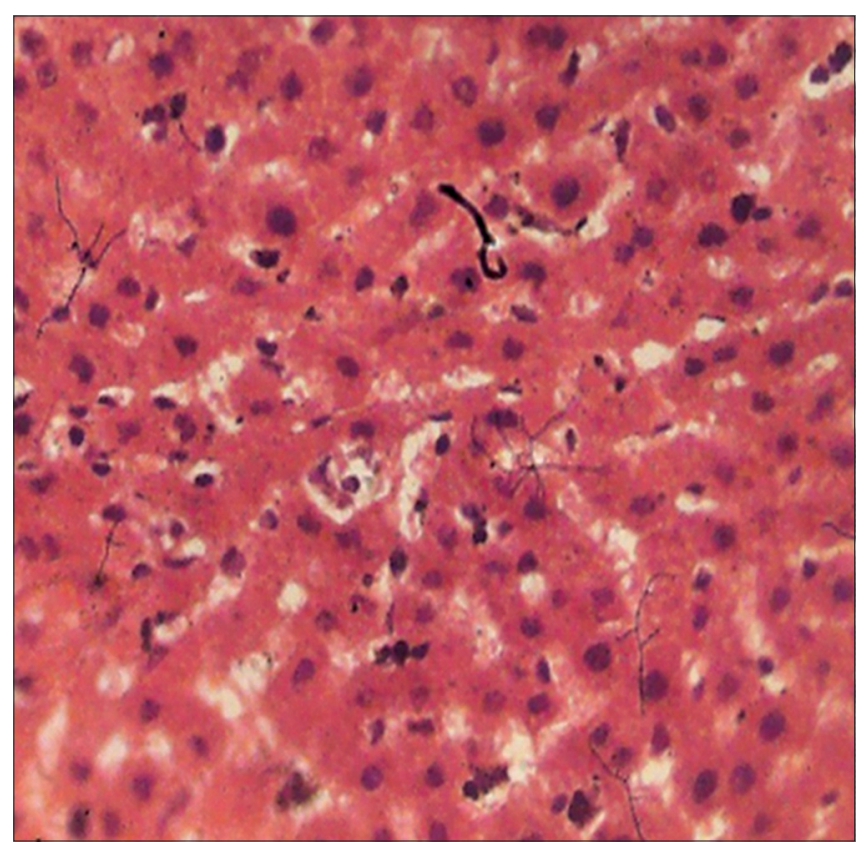

Figure 5: Histology of the liver in the control groups

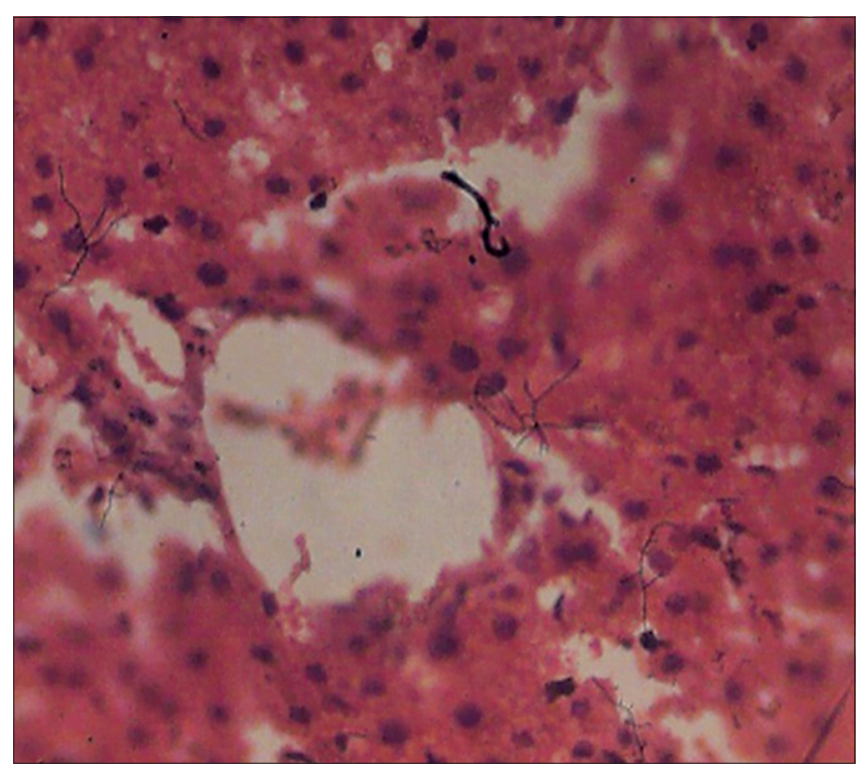

Figure 6: Histology of the liver in the DM groups

significant increases of AST and ALT in both the DM and DMT test groups compared to the control. However there was a significant reduction of AST and ALT in the DMT group compared to the DM group. This implies that OG enabled these enzymes levels that were originally raised in DM to return to normal levels.

ALT and AST are liberated into the blood whenever liver cells are damaged and increased plasma enzymes activity is a sensitive index of hepatic damage. ${ }^{12}$ Neither of these enzymes is specific to the liver but ALT occurs in much higher concentration in the liver than elsewhere. Therefore, increased serum ALT activity more specifically reflects

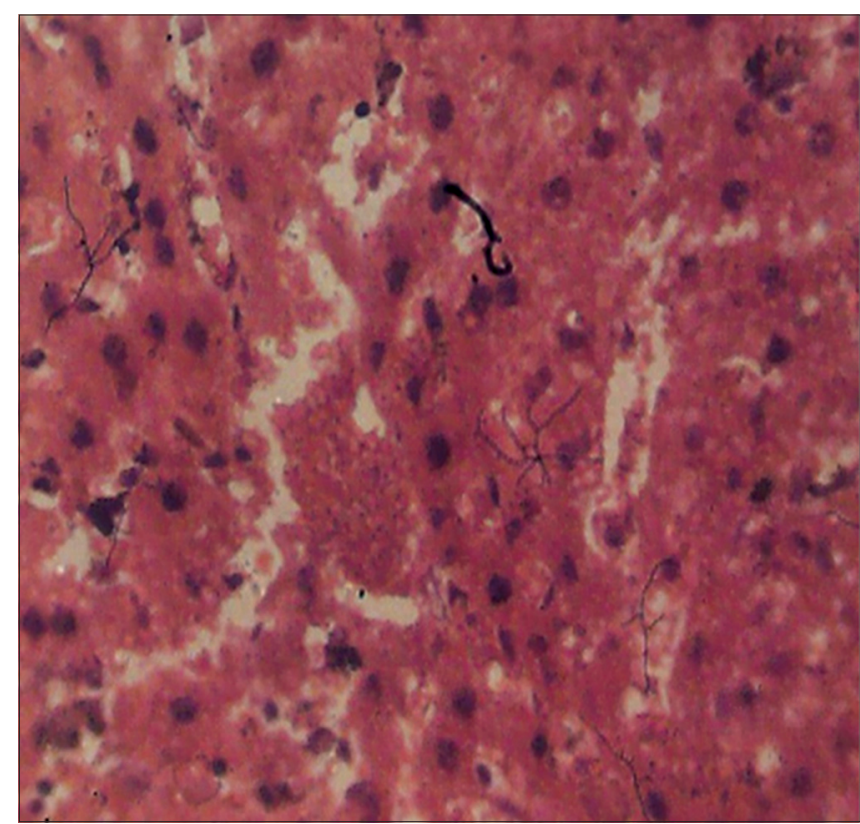

Figure 7: Histology of the liver in the DMT groups

hepatic damage. ${ }^{12}$ Thus, OG protects the integrity of liver cells (i.e. it is hepatoprotective). The actual phytochemical constituent of OG that offers this potency is of interest in future research work.

ALP level was raised in the DMT group compared to the control and the DM groups. Blood normally contains ALP derived mainly from bone and liver, and in pregnancy, additional activity of placental origin was also found. ${ }^{12}$ Thus increased osteoblastic activity from bone may be an alternative origin of a raised ALP. In biliary tract obstruction at any level, new alkaline phosphatase is synthesized in the hepatocyte membrane, much of which escapes into the blood. ${ }^{12} \mathrm{~A}$ greatly increased plasma ALP activity is therefore, the main biochemical indicator of biliary obstruction. There is therefore a tendency that OG treatment may aggravate biliary obstruction or increased osteoblastic activity of the bone, initiated by DM. The actual agent possibly implicated in this process is not known. This finding gives credence to the report by De Santis et al, ${ }^{13}$ of a significant association of the prevalence of gallstones in diabetic populations the majority of which are composed of cholesterol.

Apart from the presence of fat cells and increased number of Kuppfer cells in the DM and DMT groups, the histological presentation of the liver in the three groups were largely normal. This finding indicates that $O G$ administration is not harmful to the liver and also supports previous report that DM predisposes to fatty liver disease. ${ }^{14}$

The rate of biliary secretion was highest in the DMT group, followed by the control and lowest in the DM group. The 
enhanced rate of bile secretion in the DMT group may not be unconnected with the hepato-protective property of OG earlier reported in this study. The CCK-like effect of OG earlier reported in this study, appears to be confirmed with this observation, since CCK increases gall bladder contraction, which in turn increases bile secretion. The lowest rate of biliary secretion in the DM group clearly demonstrates the report by De Boer et al, ${ }^{15}$ that during acute hyperglycemia, gallbladder motor function is dosedependently impaired in both healthy subjects and patients with T1DM. The decreased rate of bile secretion in the DM group could also be due to autonomic neuropathy, secondary to chronic hyperglycemia; ${ }^{16}$ implying that OG could possibly alleviate autonomic neuropathy in DM to an appreciable extent.

Also in line with the finding of Lam et al, ${ }^{17}$ it is possible that treatment of diabetic rats with OG could mimic the effect of exogenous CCK administration. This postulation is further supported by the observation in this study that the DMT group of rats had the highest rate of bile secretion. This means that OG may exert a cholagogue effect just as CCK.

\section{CONCLUSION}

Results from this study have consistently supported previous report of structural and functional hepatic impairment in DM. Moreover, OG has been observed to ameliorate effectively these diabetic complications, including enhancement of bile secretion. These findings lay credence to the likely hepato-protective property of OG.

\section{REFERENCES}

1. Petrides AS. Liver disease and diabetes mellitus. Diabetes Review1994; 2:2-18.

2. Finlayson C, Hoffman J, Yeung R, Kessler H, Guttmann M, Shaer A and Clair M. Intraoperative ultrasound does not improve detection of liver metastases in resectable pancreatic cancer. Am J Surg 1998; 175:99-101.

3. Edwards CRW, Bouchier IAD, Haslett C and Chilvers EE. Diabetes Melittus in Davidson's Principle and Practice of Medicine $\left(10^{\text {th }}\right.$ Edition) Churchhill Livingstone, London. 2008;724-774.

4. Linda SC. Gastrointestinal system and endocrinology. Board review series physiology (3rd Edition). Lippincott Williams \& Wilkins. 1998;41-83.

5. Katbamna BH, Petrelli $\mathrm{M}$ and McCullough AJ. The liver in diabetes mellitus and hyperlipidaemia. In Zakim D, Boyer TD (eds), Hepatology. A Textbook of Liver Disease, $2^{\text {nd }}$ ed. W.B. Saunders: Philadelphia. 1990;73-84.

6. Lorke D. A new approach to practical acute toxicity testing. Arch. Toxicol. 1983;54: 275-287.

7. Trease GE, Evans WC. Trease and Evans' Pharmacognosy: A Physician's Guide to Herbal Medicine. $13^{\text {th }}$ Edition, Bailliere Tindall London. 1984.

8. Sofowora LA. Medicinal plants and traditional medicine in Africa. Spectrum Books Ltd, Ibaban. 1984;82-85.

9. Reitman, Frankel. Determination of Alanine Aspartate Aminotransferases. Using End point Colorimetric Diagnostic Kit (Randox Laboratory UK). 1952.

10. Osim EE, Akpogomeh BA, Ibu JO and Eno AE. Experimental Physiology Manual, Department of Physiology, University of Calabar, Calabar $3^{\text {rd }}$ ed.2004

11. Vickers S, Duncan SA, Chen I-W, Rosegay A and Duggan DE. Metabolic disposition studies on simvastatin, a cholesterollowering prodrug. Drug Metab Dispos 1990;18:138-145.

12. Edwards CRW, Bouchier IAD, Haslett $C$ and Chilvers EE. Diabetes Mellitus in Davidson's Principle and Practice of Medicine (10 $10^{\text {th }}$ Edition). Churchhill Livingstone, London. 2008; 724-774.

13. De Santis A, Attili AF and Corradini SG. Gallstones and diabetes mellitus: A case control study in a free living population sample. Hepatology 1997; 25: 787-790.

14. Horowitz M and Sandor M. Gastrointestinal function in diabetes mellitus John Wiley \& Sons, Ltd., West Sussex. 2004;10-43.

15. De Boer SY, Masclee AAM and Lam WF. Effect of hyperglycemia on gall bladder motility in type 1 diabetes mellitus. Diabetologia 1994;37:75-81.

16. Cummings DE and Overduin J. Gastrointestinal regulation of food intake. Journal of Clinical Investigations 2007;117:13-23.

17. Lam WF, Gielkens HAJ, Coenraad M, Lamers CBHW, and Masclee AAM. Effect of insulin on basal and cholecystokinin stimulated exocrine pancreatic secretion in humans. Pancreas 1999;18:252-258.

\section{Authors Contribution:}

OUA - Conceived and designed the study, made the first draft of the manuscript; PAI - Statistical analysis and interpretation of data; AEO - Literature searches and manuscript preparation; All authors reviewed and approved of the final manuscript.

Source of Support: Nil, Conflict of Interest: None declared. 